\title{
HYDROTHORAX IN HEART FAILURE
}

\author{
BY
}

\author{
D. EVAN BEDFORD AND J. L. LOVIBOND
}

From the Cardiographic Department, Middlesex Hospital

Received February 17, 1941

The term " hydrothorax" was applied to clear, non-purulent, pleural effusions before percussion and auscultation were practised and before the signs of heart disease were known. The diagnosis then depended entirely on symptoms, and MacLean (1810) in an early treatise on hydrothorax wrote as follows: "when respiration is considerably impeded, especially on motion, in a horizontal posture, or on ascending an acclivity, when the countenance is at the same time pale and sallow, assumes a leaden or livid hue; the urine small in quantity, high coloured, and, on cooling, deposits a reddish or pinkcoloured sediment; the pulse irregular or intermitting; the feet, ankles, or hands swell and are colder than natural; and the patient is suddenly roused from sleep by a sense of suffocation or extreme anxiety about the praecordia, attended with palpitation; the most superficial observer will have no doubt of the presence of a watery fluid in some of the cavities of the chest, and that the person thus affected labours under the disease termed hydrothorax, or dropsy of the chest."

Morgagni (1761) described the association of hydrothorax with heart disease post-mortem and thought that, of the two, the heart lesion was more likely to be the primary condition ; but it was Corvisart (1818) who first really distinguished between hydrothorax consecutive to heart failure and idiopathic or essential hydrothorax, i.e. pleurisy with effusion. He pointed out that cardiac hydrothorax was always associated with ascites and general anasa rca Laennec (1826), though he gave an admirable and separate account of pleurisy with effusion, still recognized the two varieties of hydrothorax described by his teacher. Idiopathic hydrothorax was unilateral; symptomatic or secondary hydrothorax was bilateral and usually a terminal condition. He seems to have regarded the absence of adhesions and false membrane as the essential criterion of hydrothorax, though he admitted that the distinction from chronic pleurisy was often as difficult in the cadaver as during life, and mentioned inflammatory hydropsies as having been described. Comte (1822), in his treatise on hydrothorax, does not appear to have recognized heart disease as the cause, though signs of heart failure were often mentioned and digitalis was advocated in treatment. He regarded the palpitation and irregular pulse as due to pressure 
on the heart and therefore as characteristic of left hydrothorax or hydropericardium.

The term "cardiac pleurisy," introduced by Bucquoy (1882) and Forgeot (1885), soon became current in France, and papers by Robert (1897), Barié (1902), Rénon (1905), Roubier and Thévenet (1906), Sergent (1925), and Joly (1935) may be mentioned as important in this connection.

A distinction was drawn between hydrothorax due simply to transudation and cardiac pleurisy regarded as an inflammatory exudate secondary to pulmonary infarction, sub-pleural hæmorrhage, congestion or acute œdema of the lung (Huchard), pericarditis, or perihepatitis. This distinction depended partly on clinical considerations and partly on the nature of the effused fluid, namely, its specific gravity, chemistry, and cytology. In general, a bilateral effusion was regarded as a transudate and a unilateral one as an exudate, though it was recognized that pleural obliteration might occasionally explain a unilateral transudate of the opposite side. Beaufumé (1907) established the occurrence of unilateral hydrothorax by describing sixteen cases, in all of which the aspirated fluid had the properties of a transudate. Later, Steele (1904), Joly (1935), and others found it impossible to separate the pleural effusions of heart failure into transudates and exudates, since the qualities of the fluid were often intermediate between these two, corresponding to a " mixed type" of effusion, and our experience confirms this view.

It is now generally stated that hydrothorax is either bilateral or right-sided, which teaching dates back to the last century (Wintrich, 1854) and receives a measure of support from statistics furnished by Steele $(1896,1904)$, Stengel (1901), Beaufumé (1907), Lickint (1928), Joly (1935), and others, based on clinical or post-mortem findings. Scherf (1936), reflecting the view of the Vienna school, states that hydrothorax is bilateral or right-sided except under certain specified conditions, namely, obliterative pleurisy on the right side, left pulmonary infarct, or pericardial effusion, when a left unilateral hydrothorax may occur.

\section{Present Investigation}

In the course of routine X-ray examination of patients with heart failure, and especially while investigating the lung stasis of left heart failure, we have encountered left unilateral hydrothorax in many cases where pulmonary infarction seemed excluded, and far more frequently than can be explained in terms of the views already mentioned. In the absence of any recent statistics based on radiological diagnosis, we have investigated the distribution of hydrothorax anew. In doing so, we have included all serous pleural effusions developing coincidentally with heart failure, for which no extracardiac cause was evident. Effusions associated with pulmonary infarction and heart failure have not been excluded because we believe they are essentially transudates.

The incidence and distribution of hydrothorax was analysed in 356 cases of congestive failure (including left heart failure) encountered at the Middlesex Hospital, the National Hospital for Diseases of the Heart, and in practice. 
Radioscopy (or orthodiagram) was done as a routine in all out-patients and in those seen in the consulting room; radiography was carried out later in most cases.

An additional analysis has been made of the post-mortem findings in 109 consecutive cases dying from heart failure, from the records of the BlandSutton Institute of Pathology over a period of five years.

\section{Diagnosis}

It has been stated that in hydrothorax the clinical signs of fluid in the chest may be scanty in relation to the volume of the effusion. Certainly the interpretation of physical signs is complicated in heart failure by elevation of the diaphragm from abdominal distension. Swelling of the liver tends to exaggerate the higher level of dullness at the right lung base and may suggest fluid there when none is present, or may neutralize dullness due to a small left hydrothorax. Error in the opposite sense arises when basal dullness is wrongly attributed to pulmonary œdema which, as Laennec taught, is imperceptible to percussion. Basal râles due to pulmonary œdema usually persist with a small hydrothorax, and pleural friction is common apart from infarcts, especially when the fluid is being absorbed. Because of the difficulties mentioned, $\mathrm{X}$-rays are essential for the sure detection of small effusions; but if clinical signs of fluid are methodically sought in every case of heart failure, even if œdema is absent, a hydrothorax of appreciable size need rarely be overlooked.

Even a small hydrothorax can be recognized with certainty by radioscopy, which is far superior to radiography in this respect. In screen examination the tube can readily be centred at the upper level of the effusion, and this, combined if necessary with rotation of the patient into the oblique position, usually permits a sharp fluid level to be visualized. In films, taken with the tube centrally placed, a small effusion is often ill-defined and difficult to distinguish from congested lung or thickened pleura. In a small or medium-sized hydrothorax the fluid is mobile and fluctuates freely with movements of the diaphragm, thus making easy its distinction from pleural adhesions or lung opacities. In left hydrothorax the diaphragm is often depressed, so that the size of the effusion will be underestimated unless the left dome of the diaphragm is rendered visible by inflating the stomach with gas, which may be done as a routine by giving alternate draughts of sodium bicarbonate and tartaric acid in solution (Figs. 1 \& 2 on pp. 96 \& 97).

\section{Incidence of Hydrothorax}

In 356 consecutive cases of heart failure, hydrothorax was observed at some stage or other in 136 (38.5 per cent). This series includes patients with failure when first seen and others who developed failure while under observation. The diagnosis of hydrothorax was established in 89 cases by X-ray examination, and in 20 of the remaining 47 cases the clinical diagnosis was confirmed by 


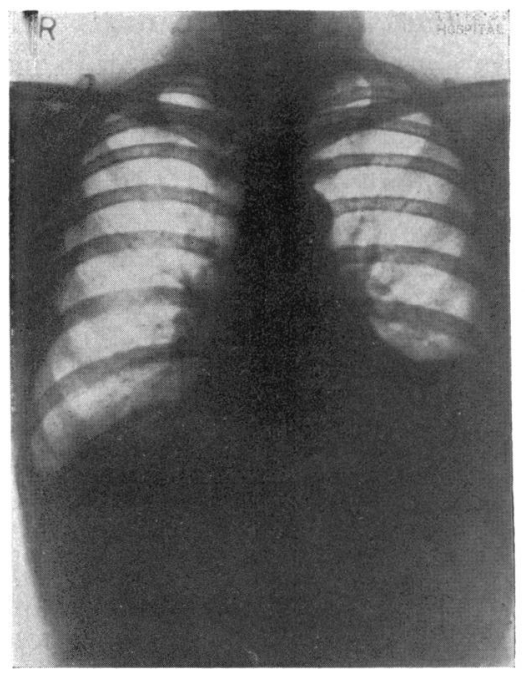

a.

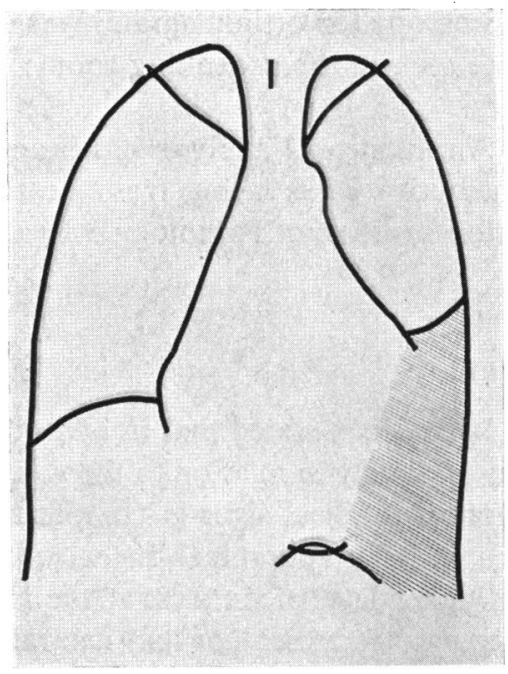

$b$.

FIG. 1.-(a) Routine radiograph showing left hydrothorax. (b) Orthodiagram after inflation of stomach with gas, showing true size of effusion and depression of diaphragm. From a woman aged 45 , with hypertension and left heart failure.

paracentesis or at necropsy. Stengel (1901) reported hydrothorax in 17 of 100 cases of heart failure, and Barié (1902) found " cardiac pleurisy" (presumably unilateral) in 10 per cent of 126 cases. These figures were based on clinical diagnosis or paracentesis, whereas ours were based mainly on radiological diagnosis which allows the inclusion of many small effusions. The frequency of hydrothorax in a series of patients with heart failure will of course increase the longer they are kept under observation, so that actual figures have little significance.

The incidence and distribution of hydrothorax in the different types of heart disease are shown in Table $\mathrm{I}$.

TABLE I

Distribution of Hydrothorax in Different Types of Heart Disease

\begin{tabular}{|c|c|c|c|c|c|c|}
\hline \multirow{2}{*}{\multicolumn{2}{|c|}{$\begin{array}{l}\text { Type of Heart } \\
\text { Disease }\end{array}$}} & \multirow{2}{*}{$\begin{array}{l}\text { Total Cases } \\
\text { of Failure }\end{array}$} & \multicolumn{4}{|c|}{ Hydrothorax } \\
\hline & & & Right & Left & Bilateral & Total \\
\hline $\begin{array}{l}\text { Hypertensive } \\
\text { Rheumatic ... } \\
\text { Arteriosclerotic } \\
\text { Thyrotoxic .. } \\
\text { Syphilitic .. } \\
\text { Myxodematous } \\
\text { Emphysematous }\end{array}$ & $\begin{array}{l}. . \\
\cdots \\
\cdots \\
\cdots \\
\cdots \\
\cdots\end{array}$ & $\begin{array}{r}136 \\
117 \\
57 \\
27 \\
16 \\
2 \\
1\end{array}$ & $\begin{array}{r}16 \\
32 \\
10 \\
7 \\
3 \\
0 \\
0\end{array}$ & $\begin{array}{r}21 \\
11 \\
4 \\
3 \\
3 \\
0 \\
0\end{array}$ & $\begin{array}{l}8 \\
7 \\
3 \\
5 \\
2 \\
1 \\
0\end{array}$ & $\begin{array}{r}45 \\
50 \\
17 \\
15 \\
8 \\
1 \\
0\end{array}$ \\
\hline TOTAL .. & .. & 356 & 68 & 42 & 26 & 136 \\
\hline
\end{tabular}


Hydrothorax (10 oz. or more) occurred in $45(41 \cdot 3$ per cent) of the 109 necropsies. This agrees closely with the post-mortem figures of Steele (1896), who found hydrothorax in 75 (43.2 per cent) of the 173 cases of failure, and of Cabot (1926) who found it in 79 (43.9 per cent) of 180 cases. The higher incidence of hydrothorax in post-mortem statistics is explained by the fact that they relate to a more advanced stage of heart failure than do clinical statistics.

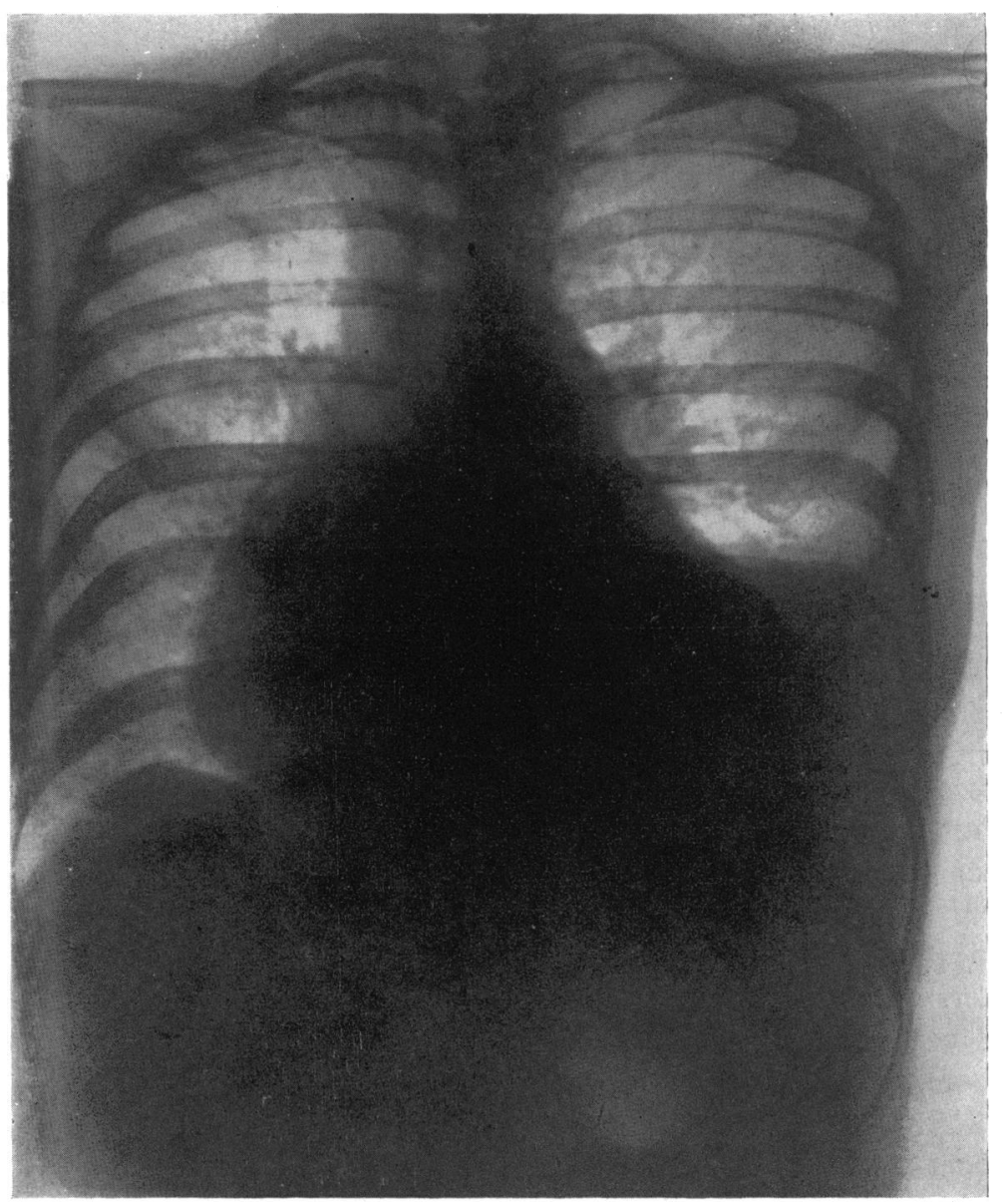

FIG. 2.-Radiograph showing chronic left hydrothorax depressing diaphragm, from a woman aged 40 with chronic hypertensive heart failure; the left chest was aspirated fourteen times. Necropsy showed no lesion of left lung.

\section{Distribution of Hydrothorax}

In our 136 cases, hydrothorax was right-sided in 68 , left-sided in 42 , and bilateral in 26; included are 11 cases of interlobar hydrothorax, 9 right and 2 left. These figures give the site of hydrothorax when first recognized; an effusion at first unilateral occasionally became bilateral. In the 45 post-mortem cases, hydrothorax was right-sided in 11, left-sided in 9, and bilateral in 25 . 
The distribution of hydrothorax previously reported is given for comparison in Tables II and III.

TABLE II

Distribution of Hydrothorax in Clinical Statistics

\begin{tabular}{|c|c|c|c|c|c|c|}
\hline \multicolumn{3}{|c|}{ Author } & $\begin{array}{c}\text { Cases of } \\
\text { Hydrothorax }\end{array}$ & Right & Left & Bilateral \\
\hline $\begin{array}{l}\text { Steele } \\
\text { Stengel } \\
\text { Forgeot } \\
\text { Lickint } \\
\text { Lord } \\
\text { Joly }\end{array}$ & $\begin{array}{l}\ldots \\
\ldots \\
\ldots \\
\ldots \\
\ldots\end{array}$ & $\begin{array}{l}\ldots \\
\ldots \\
\ldots \\
\cdots \\
\ldots\end{array}$ & $\begin{array}{l}27 \\
17 \\
25 \\
60 \\
30 \\
82\end{array}$ & $\begin{array}{r}11 \\
5 \\
13 \\
23 \\
16 \\
40\end{array}$ & $\begin{array}{l}5 \\
3 \\
7 \\
1 \\
6 \\
6\end{array}$ & $\begin{array}{r}11 \\
9 \\
5 \\
36 \\
8 \\
36\end{array}$ \\
\hline \multicolumn{2}{|c|}{ Total } & . & 241 & 108 & 28 & 105 \\
\hline \multicolumn{2}{|c|}{ Present Series } & . & 136 & 68 & 42 & 26 \\
\hline
\end{tabular}

TABLE III

Distribution of Hydrothorax in Post-mortem Statistics

\begin{tabular}{|c|c|c|c|c|c|c|}
\hline \multicolumn{3}{|c|}{ Author } & $\begin{array}{c}\text { Cases of } \\
\text { Hydrothorax }\end{array}$ & Right & Left & Bilateral \\
\hline $\begin{array}{l}\text { Steele } \\
\text { Cabot }\end{array}$ & $\begin{array}{l}\cdots \\
\cdots\end{array}$ & $\begin{array}{l}\ldots \\
\ldots\end{array}$ & $\begin{array}{l}75 \\
76\end{array}$ & $\begin{array}{l}10 \\
14\end{array}$ & $\begin{array}{r}3 \\
10\end{array}$ & $\begin{array}{l}62 \\
52\end{array}$ \\
\hline & & . & 151 & 24 & 13 & 114 \\
\hline Presen & eries & . & 45 & 11 & 9 & 25 \\
\hline
\end{tabular}

In comparison with previous records, ours show a high incidence of unilateral hydrothorax, and this requires explanation. We believe that pleural transudation often starts on one side of the chest before the other and that hydrothorax is commonly unilateral in its early stage. In response to treatment this process is reversed, and a bilateral hydrothorax disappears first on one side and then on the other. Our figures are based largely on radiological diagnosis in outpatients and therefore apply especially to the early and unilateral stage of hydrothorax. Post-mortem figures, on the other hand, relate to the terminal stages of heart failure and therefore show a relatively high incidence of bilateral hydrothorax.

In the clinical statistics tabulated, the average ratio of right- to left-sided effusions is only 3.8 to 1 , and in the pathological statistics 2 to 1 , which scarcely justifies the sweeping statements as to the predominance of right-sided hydrothorax found in most text-books. In our series based on radiological and clinical findings the average ratio of right- to left-sided effusions was 1.6 to 1 and in the pathological series 1.2 to 1 . If our figures are combined with those quoted, both clinical and pathological, we find that, in 573 cases, hydrothorax was right-sided in 211 , left-sided in 92 , and bilateral in 270 , giving a ratio of right- to left-sided effusion of just over 2 to 1 .

Our series contains a far higher proportion of left-sided effusions than has generally been reported, but so do post-mortem statistics. As already stated, 
many of the cases included in this analysis were encountered in the course of an investigation of the pulmonary stasis of left heart failure, in which, as we shall show, hydrothorax is usually left-sided. Admittedly this may have influenced our figures, but, even so, we believe that clinical observation has tended to exaggerate the preponderance of right hydrothorax, possibly because dullness due to elevation of the liver has either been mistaken for fluid or has caused a small left hydrothorax to be overlooked.

\section{Distribution of Hydrothorax in Different Kinds of Heart Disease}

It will be observed from Table I that in hypertensive heart failure left hydrothorax is appreciably more frequent than right, while in rheumatic heart disease right hydrothorax is thrice as frequent as left. The rheumatic group, consisting mainly of mitral stenosis, represents a predominantly right heart failure and hypertension a predominantly left heart failure. Before considering the significance of this relationship, we may note the influence of the heart rhythm (see Table IV).

TABLE IV

Distribution of Hydrothorax in Relation to Heart Rhythm

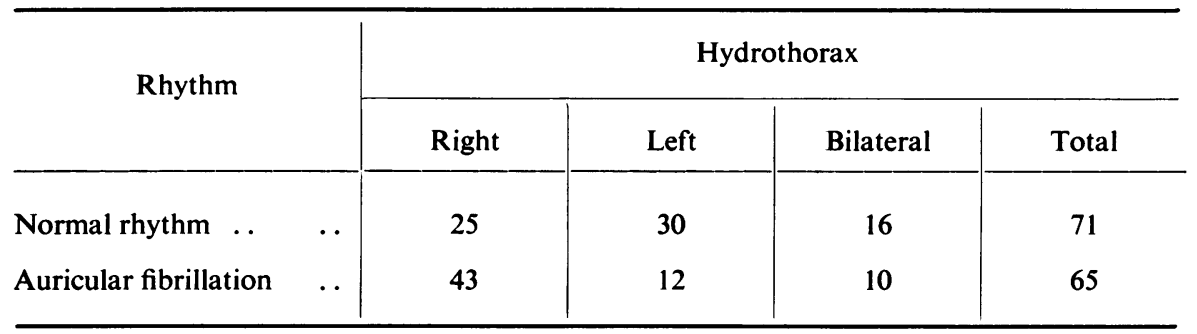

In failure with normal rhythm left hydrothorax is rather more frequent than right, but in failure with fibrillation right hydrothorax is almost four times as frequent as left. The influence of rhythm is partly explained by the fact that normal rhythm is common in hypertensive failure and fibrillation in rheumatic failure, but not entirely, since the effect of rhythm still holds in certain ætiological groups (Table V).

TABLE V

Distribution of Hydrothorax in Normal Rhythm and Fibrillation

\begin{tabular}{|c|c|c|c|}
\hline \multirow{2}{*}{ Heart Lesion } & \multirow{2}{*}{ Rhythm } & \multicolumn{2}{|c|}{ Hydrothorax } \\
\hline & & Right & Left \\
\hline Hypertension & $\begin{array}{l}\text { Normal } \\
\text { Fibrillation }\end{array}$ & $\begin{array}{r}10 \\
6\end{array}$ & $\begin{array}{r}19 \\
2\end{array}$ \\
\hline Rheumatic disease & $\begin{array}{l}\text { Normal } \\
\text { Fibrillation }\end{array}$ & $\begin{array}{r}7 \\
26\end{array}$ & $\begin{array}{l}5 \\
6\end{array}$ \\
\hline Aortic disease & $\begin{array}{l}\text { Normal } \\
\text { Fibrillation }\end{array}$ & $\begin{array}{l}5 \\
7\end{array}$ & $\begin{array}{l}8 \\
2\end{array}$ \\
\hline
\end{tabular}


Thus in hypertension and aortic disease, left hydrothorax predominates with normal rhythm and right hydrothorax with fibrillation. Similarly, in the rheumatic group, the incidence of left hydrothorax is higher in cases with normal rhythm than in those with fibrillation. The significance of this is discussed later.

\section{Hydrothorax in Left Heart Failure}

Hydrothorax in the absence of odema has long been recognized, but that it may be part of the pulmonary congestion of left ventricular failure is not yet generally appreciated. In a previous publication (Bedford, 1939) it has been shown that hydrothorax may follow attacks of pulmonary œedema and that it may occur in hypertension, coronary occlusion, and syphilitic heart disease in the absence of or before signs of systemic congestion.

Our present series includes 24 cases of left heart failure with hydrothorax: in 9 the congestion remained confined to the lungs, and in the remainder hydrothorax preceded appreciable signs of systemic congestion. The hydrothorax was left-sided in 20 cases, right-sided in 2 , and bilateral in 2 . In a series of 154 cases of left ventricular failure Bedford observed hydrothorax in 38: it was left-sided in 18, right-sided in 9, and bilateral in 11; three cases had interlobar effusions. Normal rhythm was present in all cases. Thus hydrothorax in left heart failure has a definite predilection for the left side of the chest (see Figs. $1,2,3, \& 5)$. The following cases are briefly quoted as examples of left heart failure with hydrothorax and pulmonary œdema.

Case 1. Hypertension, coronary occlusion, paroxysmal dyspncea, left hydrothorax

Male, aged 64, first seen 23.5.35.

History. Coronary thrombosis three years previously, since which he had been liable to anginal pain on effort. Severe anginal pain at rest five weeks ago, followed by nocturnal dyspnœa and pulmonary œdema.

Examination. Pulse 90, regular. Arteries thickened. Blood pressure 195/115 $\mathrm{mm}$. Apex-beat displaced to left, systolic murmur at apex. No œdema, cervical veins not engorged, liver not enlarged. Râles at both lung bases and dullness at left base. X-ray: pulmonary congestion and left hydrothorax. Cardiogram : inversion of $T_{2}$ and $T_{3}$. Treated by digitalis and salyrgan, and by aspiration of left chest. He recovered and went abroad, but died in November 1936.

\section{Case 2. Hypertension, paroxysmal dyspnea, bilateral hydrothorax}

Male, aged 39, first seen 23.8.35.

History. Hypertension recognized for several years. For 9 months subject to paroxysms of nocturnal dyspnœa, recently severe, with blood-stained expectoration.

Examination. Regular pulse. Arteries thickened. Blood pressure 205/160 mm., marked alternation. Slight enlargement of heart to left; gallop rhythm at apex. Cervical veins not distended; no œedema; liver edge just palpable. Râles over both lungs and dullness at left base. X-ray : a large left and a smaller right hydrothorax. Cardiogram : left axis deviation, QRS splintered, $T_{1}$ negative. Treated by digitalis and salyrgan, and aspiration of left chest. Lungs became dry and hydrothorax cleared completely; he returned to work for six months, after which pulmonary congestion recurred, and he died in March 1936. 


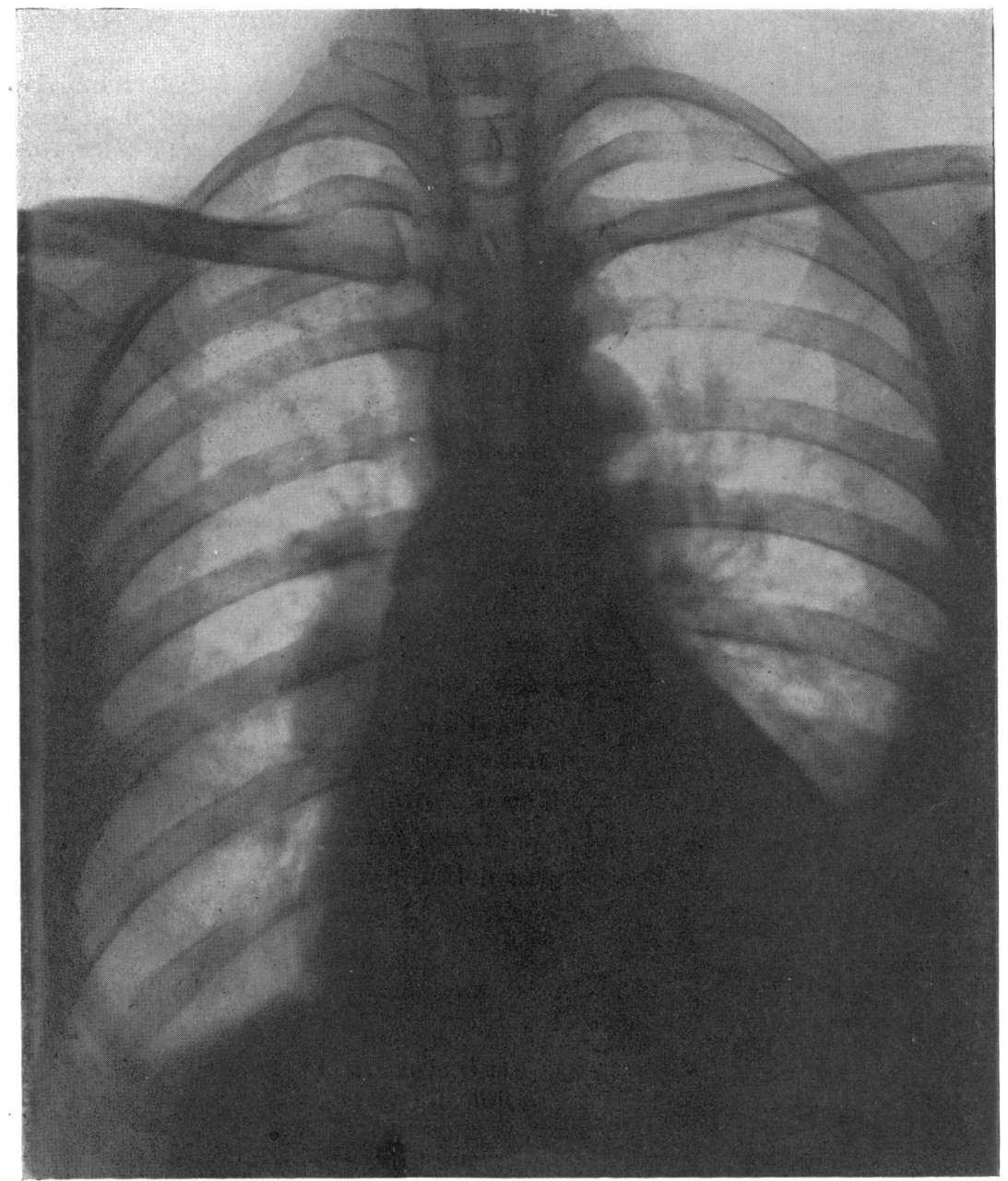

FIG. 3.--Radiograph showing left hydrothorax in a man aged 44, with hypertension and paroxysmal dyspnœa.

Case 3. Hypertension, paroxysmal dyspncea, left hydrothorax

Male, aged 53, first seen 3.5.37.

History. Paroxysmal dyspnœa and nocturnal cough for 4 months, treated as bronchitis.

Examination. Pulse 128, regular. Arteries thickened. Blood pressure 170/110 $\mathrm{mm}$. Slight pulsus alternans. Gallop rhythm at apex. No œdema; cervical veins not distended; liver palpable. Râles at both lung bases and dullness at left base. X-ray : pulmonary congestion and left hydrothorax; moderate cardiac enlargement. Cardiogram: normal rhythm, QRS splintered and $T_{1}$ negative. W.R. negative. Venous pressure, $10 \mathrm{~cm}$. Arm to tongue circulation time (decholin), 28 secs. Treated with digitalis and salyrgan, the hydrothorax cleared up while in hospital.

Case 4. Aortic incompetence, probably syphilitic, paroxysmal dyspneea, hydrothorax Male, aged 60, admitted to hospital 22.7.38.

History. No rheumatic fever or chorea. For 7 months subject to attacks of 
nocturnal dyspnœa with cough, wheezing, and frothy expectoration. Occasional sternal pain unrelated to effort.

Examination. Pulse regular, collapsing. Blood pressure $140 / 50 \mathrm{~mm}$. Heart enlarged to left; aortic diastolic murmur. No odema, no distension of cervical veins, liver not enlarged. Dullness and râles at left lung base. X-ray : dilated ascending aorta, right interlobar and left basal hydrothorax. Cardiogram : left axis deviation, QRS splintered, $T_{1}$ and $T_{2}$ negative. W.R. negative. He improved with treatment and left hospital, but died suddenly in December 1938.

\section{Obliterative Pleurisy in Relation to Hydrothorax}

In the 109 necropsies of heart failure that were analysed and in the 23 necropsies on our own cases, making 132 in all, complete obliteration of one or both pleural cavities occurred nine times; in seven the left pleural sac was obliterated, in one the right, and in one both sides. In five cases there was a contralateral hydrothorax, in the others none. Thus, obliterative pleurisy does occasionally explain a unilateral hydrothorax, though rarely in our cases a left-sided one. Pleural adhesions of some degree were of course common, and often involved the same side as the effusion. Where hydrothorax was recent there was usually little pleural change, but where it was chronic the pleura was sometimes much thickened, and in several cases there was atelectatic bronchiectasis of the lung on the affected side.

\section{Pulmonary Infarction in Relation to Hydrothorax}

In our 356 cases of heart failure, pulmonary infarction was recognized at some period in 46: 33 of these also had hydrothorax, but in only 13 of these could the hydrothorax be regarded as the sequel of infarction; 8 were rightsided and 5 left-sided effusions. In the remainder these two conditions seemed to be unrelated, either because hydrothorax preceded the infarct, or because the two occurred at different periods; in three cases the infarct and the hydrothorax were on the opposite sides.

Thus, as far as clinical observation goes, hydrothorax could only be attributed to infarction in 13 of 136 cases. Necropsies were obtained in 23 cases, in 9 of which there were lung infarcts, 5 on the right side, 3 on the left, and 1 bilateral. Hydrothorax was present in 8 of these 9 cases; in 4 it was bilateral, and in 4 unilateral and on the same side as the infarct. In the 109 post-mortem records analysed, lung infarcts were recorded in 42 cases, of which 20 also had hydrothorax.

It is difficult to draw any precise conclusions as to the rôle of pulmonary infarction in the causation of hydrothorax. In the terminal stages of heart failure, they are frequently associated, but even so a causal relationship must not be assumed too readily, for hydrothorax may precede the infarct or may be bilateral when the infarct is unilateral. Furthermore, in the absence of heart failure, for example after surgical operations, infarction does not usually cause an appreciable pleural effusion. If, as we believe, hydrothorax is a sequel of pulmonary venous engorgement, then the presence of an infarct in addition is 
not of much consequence, apart from causing some degree of inflammatory reaction in the pleural transudate.

The average hydrothorax recognized clinically is by no means a terminal event, for in half of our cases it cleared up completely within a few weeks or months in response to treatment, rarely leaving any residual signs, and there is no reason to believe that pulmonary infarction was at all common. Chronic hydrothorax, on the other hand, does appear often to be associated with an infarct.

\section{Interlobar Hydrothorax}

There were 11 cases of interlobar hydrothorax in this series, 9 right- and 2 leftsided. An anterior radiograph shows a sharply defined lemon-shaped shadow in the right lung field (Fig. 4), or a more diffuse mid-zone opacity. An oblique or lateral view may demonstrate the effusion better. At least 29 cases of interlobar hydrothorax have previously been reported (Stewart, 1928; Kiser,

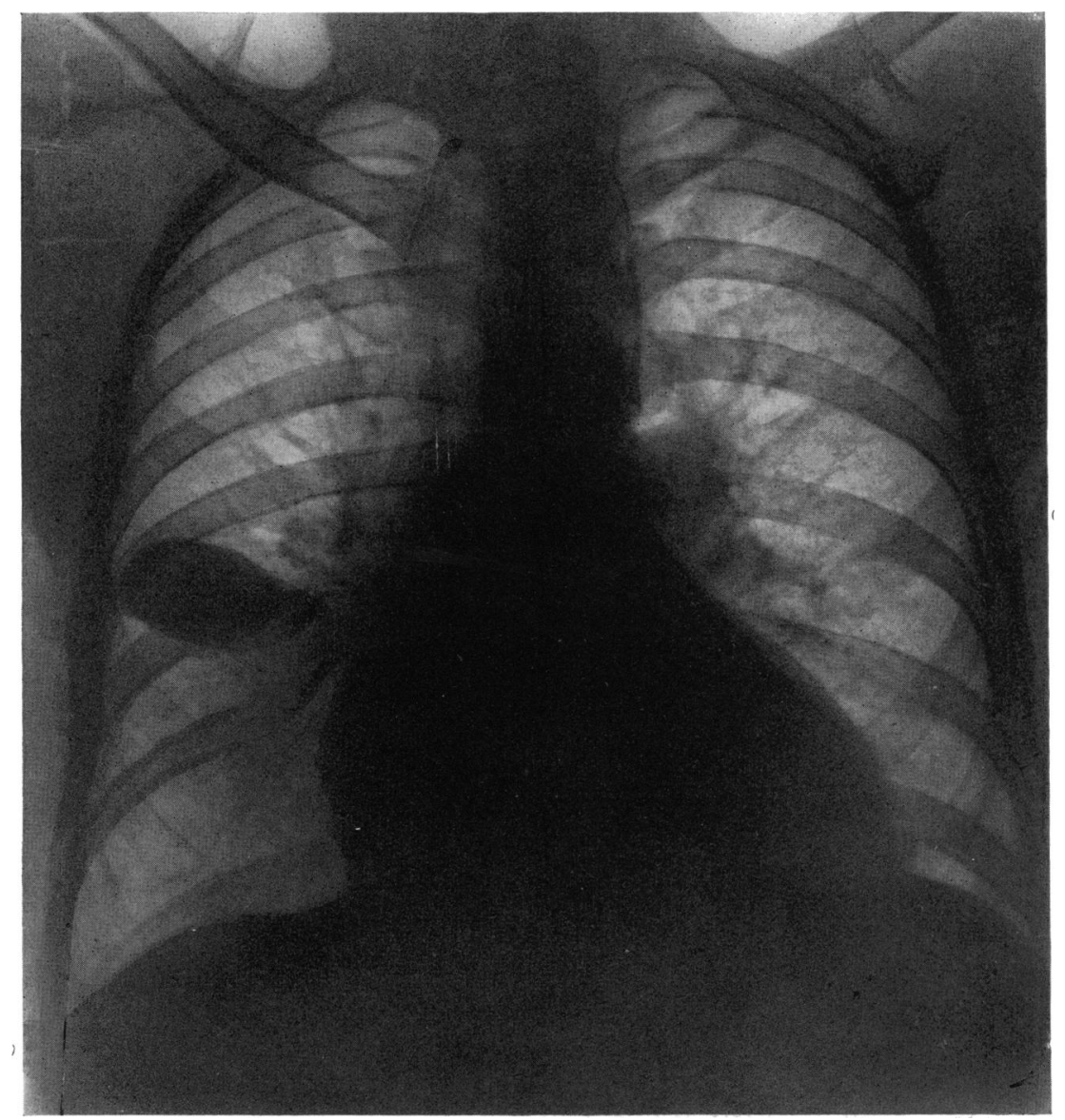

FIG. 4.- Radiograph showing pulmonary congestion and right interlobar hydrothorax, from a man aged 67 , shortly after coronary occlusion; no œdema or systemic congestion. 
1929; Freedman, 1931; Steele, 1931; Austrian, 1932; Vessel, 1932; Stein and Schwedel, 1934; Shiflett, 1935), apparently all right-sided and usually situated between the upper and middle lobes.

The occurrence of interlobar hydrothorax is usually attributed to obliteration of the main pleural cavity by adhesions, and post-mortem confirmation of this has been recorded (Stewart, 1928). Such an explanation is not always applicable, as in five of our cases there was also an effusion in the main pleural cavity (Fig. 5). Stein and Schwedel suggest that there are two types of inter-

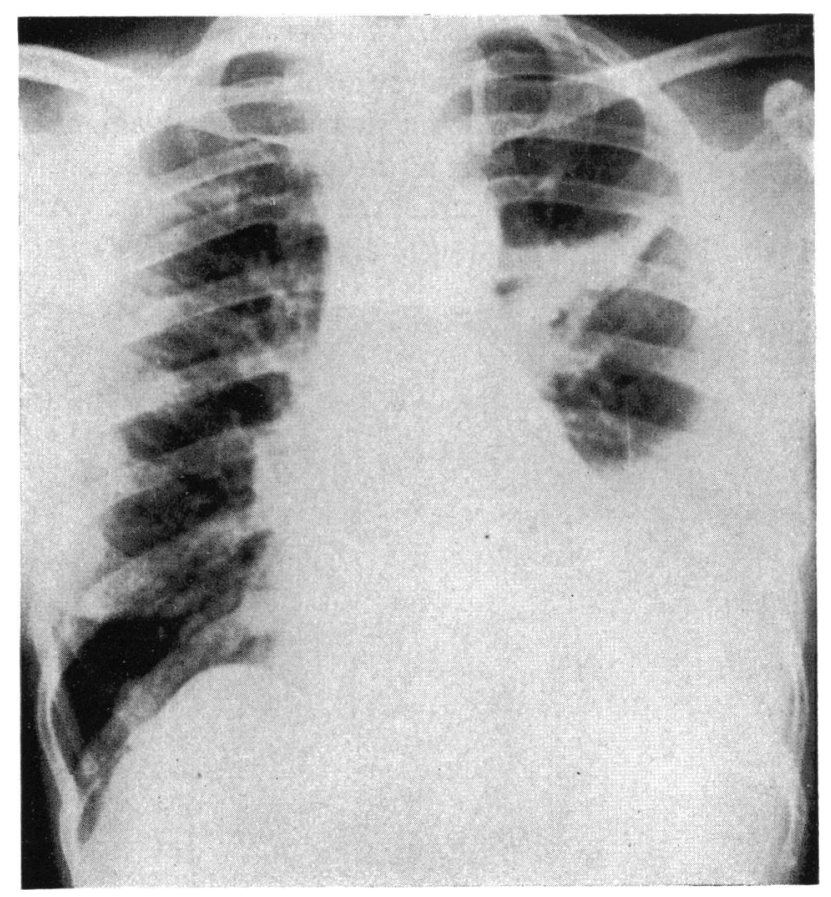

Fig. 5.-Radiograph showing left basal and small left interlobar hydrothorax, from a woman aged 47, with syphilitic aortitis and heart failure.

lobar hydrothorax, one a true encysted effusion, the other an indentation of the lung fissure, into which fluid seeps from the main pleural cavity; but this latter explanation seems to us unlikely. Zdansky (1929) points out that œdema and congestion of the lung in heart failure may be unevenly distributed and may be localized at the site of pleural thickening or pulmonary fibrosis. Radiographs often show an œematous or thickened interlobar septum in heart failure, or even a thin lamellar effusion (Fig. 6), which represents the early stage of interlobar hydrothorax. The lung fissure has no connection with the systemic (azygos) venous system, and transudation at this site can only be explained in terms of pulmonary engorgement, a point of some significance in relation to the pathogenesis of hydrothorax. 


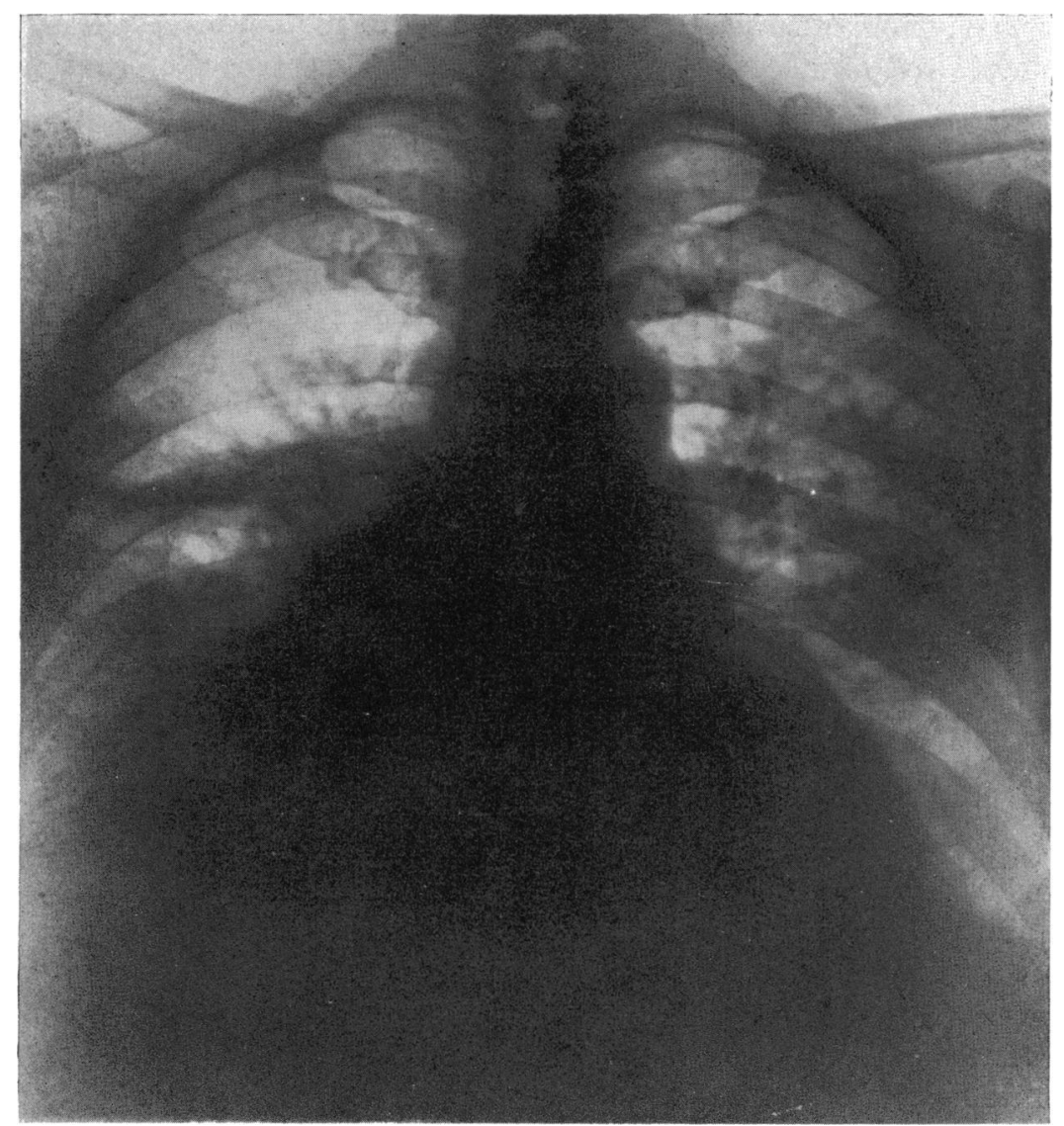

FIG. 6.- Radiograph showing pulmonary congestion and lamellar interlobar hydrothorax; right basal hydrothorax recently aspirated. From a man aged 62 , with coronary occlusion, who was free from œdema and systemic congestion.

\section{Analysis of Pleural Fluid}

Fifty samples of pleural fluid from 27 cases were investigated in respect of specific gravity, cytology, and protein content. The specific gravity, determined by dropping the fluid into xylol chloroform mixtures of known specific gravity, varied between 1005 and 1034, the average being 1011.5; even in the same patient it varied by as much as 3 or 4 points at different times.

The cell content of the centrifuged deposit varied considerably in different specimens examined. Red cells were usually plentiful. Most obvious were endothelial cells, usually discrete, but quite often in plaques of 3 to 8 cells, and constituting up to 80 per cent of all cells in some samples. Lymphocytes were always present and sometimes predominated, ranging from 5 to 70 per cent. Polymorphs were usually scanty, but occasionally accounted for 70 per cent of all cells. The average cell content in 31 specimens was: lymphocyctes 45 per cent, endothelial cells 38 per cent, and polymorphs 17 per cent. A few specimens which showed a high polymorph count were from cases of pulmonary 
infarction; more often polymorphs were absent or did not exceed 10 per cent. The usual cell formula corresponded to the " mixed type" of effusion, i.e. partly transudate, partly exudate.

The total protein ranged between 0.6 and 4.2 per cent, averaging 2.1 per cent; albumin 1.3 per cent, and globulin 0.7 per cent. Although the specific gravity and protein content of hydrothorax are usually lower than in a typical inflammatory effusion, there is considerable overlapping, and it seems doubtful if any sharp differentiation between transudate and exudate can often be made from analysis of the fluid alone. A high polymorph count and a frankly blood-stained fluid certainly suggest an infarct. Considering that pleural transudate is in contact with a chronically congested lung, it is not surprising to find that it often shows some degree of inflammatory reaction.

\section{Clinical Course of Hydrothorax}

Barié (1902) regarded true hydrothorax as a terminal event in heart failure, a view that was probably correct at the time. The advent of mercurial diuretics has contributed much towards a better outlook in these patients, and now they often survive the first appearance of hydrothorax by years. Salyrgan and similar preparations are of great value in dehydrating the lungs and pleuræ, and their use has largely obviated the need for aspiration.

In 70 of our patients the hydrothorax cleared up completely under observation, in half of them within a month and in all but 8 within nine months. In 21 cases the hydrothorax became chronic, persisting after other signs of failure had disappeared, and in 13 cases it was observed to persist for over a year (see Fig. 2), and once for 4 years. These patients were kept more or less free from œdema by digitalization and regular injections of salyrgan. In only 38 cases was hydrothorax a purely terminal event, appearing within a few months of death.

When hydrothorax cleared up within a few months, it left no residue, and $\mathrm{X}$-rays showed normal clarity of the lung base and free diaphragmatic movements. In the more chronic forms, especially when associated with pulmonary infarction, there was usually evidence of pleural thickening and adhesions.

\section{Pathogenesis}

A raised venous pressure is accepted as an essential factor in the complex process of transudation of fluid into the tissues in heart failure. The pleural sacs have both a systemic and a pulmonary venous drainage. The parietal pleural veins are systemic and drain into the superior vena cava or its tributaries-mainly by the azygos veins, which are also connected with tributaries of the inferior vena cava via the lumbar veins. The capillary network of the visceral pleura, though its arterial supply is sometimes derived from the bronchial vessels, drains almost entirely into the pulmonary veins (Miller, 1937). Hydrothorax must therefore be considered in relation both to systemic and to pulmonary venous engorgement. 
It has generally been assumed that hydrothorax is a manifestation of systemic venous stasis, and therefore ipso facto a transudate from the parietal pleura; yet there is scanty evidence to support such a view. West's case (West, 1909) of unilateral hydrothorax associated with azygos venous thrombosis, in a patient with nephritis, is usually cited, and the old azygos theory of Bacelli (1867) has so often been quoted in explanation of the supposed predominance of right-sided effusions that we have perhaps grown accustomed to thinking of hydrothorax in terms of the azygos veins. The factor of pulmonary venous stasis has certainly received inadequate consideration.

Bacelli postulated a constriction of the vena azygos major which was supposed to be stretched over the right lung root by downward traction of the dilated right heart. In fact, the diaphragm and heart ascend in heart failure, as shown by radiography, so that Bacelli's explanation must be discarded. Compression of the azygos vein by upward pressure of the dilated right auricle has also been suggested, but Fetterolf and Landis (1909) rejected this view, concluding that direct or indirect compression of the azygos by the heart was anatomically impossible. In view of the free anastamosis between the thoracic veins, compression of the vena azygos major seems to us an inadequate explanation of a right hydrothorax, and provides no explanation of a left hydrothorax. Pressure on the pulmonary veins in the right lung root was considered more likely on anatomical grounds by Fetterolf and Landis (1909) and by Steele (1896).

Fishberg (1937) has discussed the pathogenesis of hydrothorax in relation to left and right heart failure and his views deserve attention. He states that hydrothorax does not occur in isolated failure of the left heart and that pulmonary engorgement by itself cannot produce hydrothorax. He notes that hydrothorax may be absent in pure right heart failure with massive œedema and ascites, and concludes that both systemic and pulmonary stasis are requisite.

All who have investigated hydrothorax have observed that it may occur in the absence of odema, yet if a raised systemic venous pressure were mainly responsible, as generally assumed, the pleura, with its alternative pulmonary venous drainage, should be the last rather than the first site of transudation. The only satisfactory explanation of hydrothorax without œdema, if we exclude pulmonary infarction, is in terms of pulmonary stasis due to left heart failure, in which, as we have shown, hydrothorax is not infrequent. If hydrothorax were mainly due to systemic stasis we should expect to find it early and constantly in conditions of right heart failure with severe venous engorgement, yet the reverse is the case. In tricuspid disease with failure, ascites is early and hydrothorax late, and the unusual clarity of the lung fields in radiographs has often been remarked (Fig. 7, p. 108). Similarly in heart failure due to atrial septal defect, in which extreme engorgement of the right heart is the rule, pulmonary œdema and hydrothorax are noticeably absent, but ascites is common (Bedford, Papp, and Parkinson, 1941). In mitral stenosis, though failure involves mainly the right heart, there is an obstruction distal to the lungs, so that pulmonary stasis occurs early and hydrothorax is common. To sum up, hydrothorax is found in the same conditions as pulmonary œdema, namely, in left heart failure, 


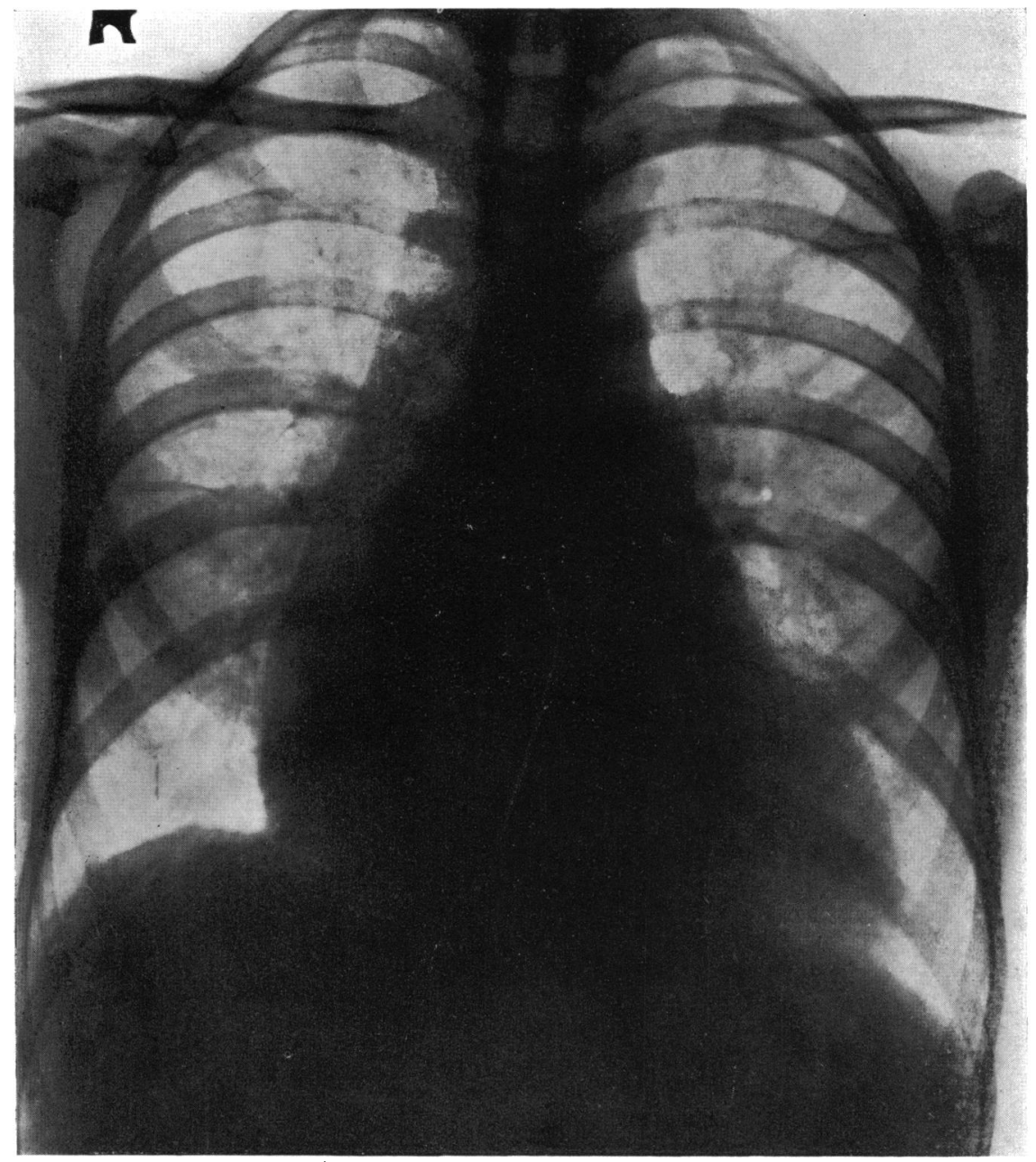

Fig. 7.- Radiograph from case of rheumatic heart disease with longstanding tricuspid incompetence and heart failure with ascites and odema. There is gross distension of vena cava and enlargement of right auricle, but lung bases are clear.

in combined left and right heart failure, and in mitral stenosis, and it is absent or late in pure right heart failure in which the lungs are spared. From this we may conclude that the essential factor in the production of hydrothorax is pulmonary engorgement, and that as long as the lungs are efficiently drained by the left heart, a rise in systemic venous pressure does not cause pleural transudation.

The occasional occurrence of interlobar hydrothorax supplies the proof that pleural transudation may occur quite independently of systemic congestion, for the interlobar pleura is not connected with the systemic veins. Similarly, when a unilateral effusion is determined by pulmonary infarction and heart failure, the visceral and not the parietal pleura is presumably the source of the fluid, which is probably a transudate with some degree of inflammatory reaction. 
Lastly, the pulmonary origin of hydrothorax must appeal to all familiar with the radiology of heart failure. When a film of the chest, especially in a patient free from ascites and œdema, shows opacity around the lung roots, an œdematous right interlobar fissure, and basal pleural fluid (Fig. 6), the inference that these are alike manifestations of pulmonary congestion is difficult to avoid. Indeed, Zdansky (1929), in his classical account of the radiology of lung stasis, gives hydrothorax as the final stage.

We can now consider unilateral hydrothorax in terms of pulmonary as opposed to systemic congestion. We refer to those cases seen in the early and unilateral stage of pleural transudation, and not to the minority in which the site is determined by local conditions such as lung infarct or contralateral pleural obliteration.

We have shown that there is a definite relation between the site of the hydrothorax and the underlying heart condition, a conclusion previously reached by Steele. Pure left-sided heart failure, hypertension, and normal rhythm favour a left-sided hydrothorax, whereas failure with auricular fibrillation favours a right-sided one. Established auricular fibrillation is almost incompatible with pure left heart failure (Bedford, 1939), for it always involves systemic as well as pulmonary congestion, and is associated with some degree of right auricular dilatation. Thus it appears that enlargement of the left heart without right auricular dilatation, e.g. pure left heart failure, favours a left hydrothorax, and that dilatation of the right heart favours a right hydrothorax. It is not difficult to believe that enlargement of the left ventricle acts unfavourably on the circulation of the lower lobe of the left lung, either directly by compression, or indirectly by pressure on or displacement of the left pulmonary veins, the lower of which lies directly behind the left ventricle. Similarly, enlargement of the right auricle may affect the right lung root and favour a right-sided hydrothorax.

Anatomical differences between the two lungs have also to be considered, and Dock (1935) has studied their hydrostatic effect in relation to the pulmonary circulation, concluding that, in the usual bodily postures, gravity favours transudation into the right side of the chest. Many other explanations of right hydrothorax have been suggested, only one of which need be mentioned, namely, the effect of a swollen liver which may hinder the movements of the right diaphragm and so impair the circulation in the base of the right lung. Provided that the influence of cardiac enlargement is equally distributed between the two sides of the chest, it seems quite possible that anatomical differences may in some way favour right-sided pleural transudation.

\section{SUMmaRY AND Conclusions}

Old and recent views on hydrothorax have been reviewed and its clinical and radiological diagnosis have been discussed.

Hydrothorax was observed at some stage in 136 ( 38.5 per cent) of 356 cases of congestive heart failure, diagnosis being mostly radiological, and in 45 (41.3 per cent) of 109 cases of failure examined post mortem. The hydrothorax was right-sided in 68 cases, left-sided in 42 , and bilateral in 26; this included 
11 interlobar effusions. Neither these nor previous statistics show right unilateral hydrothorax to be as predominant as generally supposed.

A definite relation was found between the site of the hydrothorax and the underlying heart condition. Hypertension, left heart failure, and normal rhythm favoured a left hydrothorax; mitral stenosis, combined right and left heart failure, and auricular fibrillation favoured a right hydrothorax. Clinical hydrothorax, which clears up rapidly with treatment, can rarely be attributed to pulmonary infarction, but in the terminal stages of heart failure and at postmortem examination infarction is often an associated condition.

Hydrothorax is not uncommon in left heart failure, when it is a complication of pulmonary congestion. This explains its occurrence without œdema. In pure right heart failure ascites without hydrothorax is the rule.

The pleural fluid in hydrothorax may show some degree of inflammatory reaction, probably due to its contact with chronically congested lungs, and no sharp division between transudate and exudate (cardiac pleurisy) can usually be made.

In response to treatment by mercurial diuretics, hydrothorax often clears up completely within a few weeks or months, leaving no residue; but occasionally it becomes chronic and persists for a year or longer.

The pathogenesis of hydrothorax has been discussed and reasons given for regarding it as related to pulmonary rather than systemic venous engorgement, and as a transudate from the visceral rather than the parietal pleura. Unilateral and interlobar hydrothorax can better be explained in terms of pulmonary than of systemic stasis.

We are much indebted to hospital colleagues, especially Dr. G. E. S. Ward, for permission to follow up cases admitted under their care, and to Professor James McIntosh for laboratory facilities and for permission to analyse the post-mortem records of the Bland-Sutton Institute of Pathology. One of us (J. L. L.) has to thank the Medical Research Council for a wholetime grant during a part of this investigation.

\section{REFERENCES}

Austrian, C. R. (1932). Libman Anniversary Volumes, New York, 1, 101.

Bacelli, G. (1867). Patologia del Cuore e dell'Aorta, Rome.

Barié, R. (1912). Traité pratique des Maladies du Coeur et de l'Aorte, 3rd edit., Paris.

- (1902). Semaine Méd., 22, 25.

Beaufumé (1907). Thése de Paris, No. 258.

Bedford, D. E. (1939). Lancet, 1, 1303.

Bedford, D. E., Papp, C., and Parkinson, J. (1941), British Heart J., 3, 37.

Bucquoy (1882). France Méd., cited by Barié.

Cabot, R. C. (1926). Facts on the Heart, Philad.

Comte, J. B. (1882). De l'Hydropsie de Poitrine et des Palpitations du Coeur, 2nd edit., Paris.

Corvisart, J. N. (1818). Essai sur les Maladies et les Lésions organiques du Coeur, 3rd edit., Paris.

Dock, W. (1935). Amer. Heart J., 10, 1047.

Fetterolf, G., and Landis, H. R. M. (1909). Amer. J. med. Sci., 138, 712.

Fishberg, A. M. (1937). Heart Failure, London.

Forgeot (1885). Thése de Paris.

Freedman, E. (1931). Radiology, 16, 14.

Joly, F. (1935). Thése de Paris, No. 679.

Kiser, E. F. (1929). Amer. Heart J., 4, 481.

Laennec, R. T. H. (1826). Traité de l'Auscultation Médiate, 2nd edit., Vol. II, Paris.

Lickint, F. (1928). Med. Klin., 24, 809.

Lord, F. T. (1927). Osler's Modern Medicine, Lond., Vol. IV, 272.

Lovibond, J. L. (1937). Thesis for degree of M.D. Cambridge. 
Maclean, L. (1810). On Hydrothorax, Sudbury.

Miller, W. S. (1937). The I.ung, London.

Morgagni, J. B. (1761). De Sedibus et Causis Morborum.

Rénon, L. (1905). Bull. Méd., 19, 453.

Robert, J. (1897). Thése de Paris, No. 106.

Roubier, C., and Thévenet (1906). Gaz. d'Hôp., Paris, 79, 1047.

Sergent, E. (1925). Journ. de Méd. et Chir. Prat., Paris, 96, 201.

Scherf, D. (1936). Klinik und Therapie der Herz Krankheiten, und der Gefässerkrankungen, 3rd Auflage, Wien.

Shiflett, E. L. (1935). Radiologv, 25, 429

Steele, J. D. (1896). Univ. Med. Mag. Philadelph., 9, 563.

- (1904). J. Amer. med. Ass., 43, 927.

Steele, J. M. (1931). Amer. Heart J., 7, 212.

Stein, J. D., and Schwedel, J. B. (1934). Amer. Heart J., 10, 230.

Stengel, A. (1901). Univ. Penn. M. Bull. Philad., 14, 103.

Stewart, M. J. (1928). Amer. Heart J., 4, 227.

Vessel, H. (1932). Med. J. \& Record, 135, 576.

West, S. (1909). Diseases of the Organs of Respiration, 2nd edit., London.

Wintrich, M. A. (1854). Virchows Handbuch der Spec. Path. u. Therapie, Vol. V, Erlangen.

Zdansky, E. (1929). Wien. Arch.f. inn. Med., 18, 461. 